\title{
Effect of monomeric adiponectin on cardiac function and perfusion in anesthetized pig
}

\author{
Elena Grossini', Flavia Prodam ${ }^{2}$, Gillian Elisabeth Walker², Lorenzo Sigaudo', \\ Serena Farruggio', Kevin Bellofatto', Patrizia Marotta', Claudio Molinari', \\ David Mary', Gianni Bona ${ }^{2}$ and Giovanni Vacca' \\ 'Laboratory of Physiology and Experimental Surgery, Department of Translational Medicine, \\ University Eastern Piedmont 'A. Avogadro', Via Solaroli 17, Azienda Ospedaliera Universitaria Maggiore della \\ Carita, Corso Mazzini 36, I-28100 Novara, Italy \\ 2Pediatric Unit, Department of Health Sciences, University Eastern Piedmont 'A. Avogadro', Via Solaroli 17, \\ Azienda Ospedaliera Universitaria Maggiore della Carità, Corso Mazzini 36, I-28100 Novara, Italy
}

\author{
Correspondence \\ should be addressed \\ to E Grossini \\ Email \\ grossini@med.unipmn.it
}

\begin{abstract}
Adiponectin, the most abundant adipokine released by adipose tissue, appears to play an important role in the regulation of vascular endothelial and cardiac function. To date, however, the physiological effects of human monomeric adiponectin on the coronary vasculature and myocardial systo-diastolic function, as well as on parasympathetic/sympathetic involvement and nitric oxide (NO) release, have not yet been investigated. Thus, we planned to determine the primary in vivo effects of human monomeric adiponectin on coronary blood flow and cardiac contractility/relaxation and the related role of autonomic nervous system, adiponectin receptors, and NO. In 30 anesthetized pigs, human monomeric adiponectin was infused into the left anterior descending coronary artery at constant heart rate and arterial blood pressure, and the effects on coronary blood flow, left ventricular systo-diastolic function, myocardial oxygen metabolism, and NO release were examined. The mechanisms of the observed hemodynamic responses were also analyzed by repeating the highest dose of human monomeric adiponectin infusion after autonomic nervous system and NO blockade, and after specific adiponectin 1 receptor antagonist administration. Intracoronary human monomeric adiponectin caused dose-related increases of coronary blood flow and cardiac function. Those effects were accompanied by increased coronary NO release and coronary adiponectin levels. Moreover, the vascular effects of the peptide were prevented by blockade of $\beta_{2}$-adrenoceptors and NO synthase, whereas all effects of human monomeric adiponectin were prevented by adiponectin 1 receptor inhibitor. In conclusion, human monomeric adiponectin primarily increased coronary blood flow and cardiac systo-diastolic function through the involvement of specific receptors, $\beta_{2}$-adrenoceptors, and NO release.
\end{abstract}
Key Words
- adipokine
- autonomic nervous system
- heart function
- nitric oxide

Journal of Endocrinology (2014) 222, 137-149

\section{Introduction}

Both animal and clinical investigations have suggested that inflammation and dysfunction of adipose tissue could be involved in the onset of cardiovascular disease
(Mazurek et al. 2003, Xu et al. 2010). Hence, peptides released by pericardial adipose tissue have been found to play a significant role in conditions such as the metabolic 
syndrome, with the adipose tissue surrounding the heart being clinically associated with coronary artery disease (Ouwens et al. 2010). In this respect, it is suggested that adipokines produced by adipose tissue would act as local 'vasocrine' agents in influencing a wide spectrum of hemodynamic, metabolic, and immunologic factors, including vascular reactivity, endothelial dysfunction, and vascular remodeling (Eringa et al. 2012, Gu \& Xu 2013).

Adipokines are involved in a 'good-bad', yin-yang homeostatic balance whereby there are substantial benefits: cardioprotection, promoting endothelial function, angiogenesis, and reducing hypertension, atherosclerosis, and inflammation (Mattu \& Randeva 2013). Adiponectin, the most abundant protein secreted by the adipose tissue (Arita et al. 1999) and circulating in human plasma as multimeric forms (Liu \& Liu 2012), has been associated with endothelial improvement and vascular protection (Beltowski et al. 2008, Zhu et al. 2008) through the activation of an endothelial isoform of nitric oxide (eNOS)-related signaling, with antiinflammatory (Ouchi \& Walsh 2007) and antiatherogenic properties (Barseghian et al. 2011). It is also of interest that numerous epidemiological studies have correlated decreased adiponectin levels with an increased risk of cardiovascular disease in obesity and diabetes (Kumada et al. 2003, Pischon et al. 2004, Frystyk et al. 2007) and with coronary artery disease (Hara et al. 2007). As such, adiponectin deficiency has been reported to be predictive of future adverse cardiac events (Kojima et al. 2006) and has been associated with increased oxidative stress and inferior recovery in cardiac function (Shibata et al. 2008).

Moreover, adiponectin has been found to stimulate the production of NO in vascular endothelial cells (Chen et al. 2003), and hypoadiponectinemia has been associated with an impaired endothelium-dependent vasodilation (Tan et al. 2004), which is a predictor of coronary events. However, little is known about the physiological role of monomeric adiponectin in the in vivo acute modulation of cardiac perfusion and function, as well as any related involvement of the autonomic nervous system. There is very little information available regarding this issue, only in the form of hypotensive action elicited by adiponectin in anesthetized rats, which has been found to be partly related to changes in sympathetic nerve activity (Tanida et al. 2007).

Thus, the present study was planned in controlled experiments performed in anesthetized pigs to investigate the primary in vivo effects of human monomeric adiponectin on cardiac contractility and coronary blood flow and the mechanistic involvement of autonomic nervous system, subtype 1 of adiponectin receptors (AdipoR1) and of NO.

\section{Materials and methods}

The experiments were carried out in accordance with UK legal requirements, the ARRIVE (Animal Research: Reporting In Vivo Experiments) guidelines, the national guidelines (DLGS 27/01/1992, license no. 116), and with the approval of the Local Ethical Committee.

\section{Animal instrumentation and measurements}

The experiments were carried out in 30 domestic pigs, weighing $64-73 \mathrm{~kg}$, supplied by an accredited dealer (Azienda Invernizzi, Olengo, Novara, Italy). After being fasted overnight, the pigs were anesthetized with i.m. ketamine $(20 \mathrm{mg} / \mathrm{kg}$, Parke-Davis, Detroit, MI, USA), followed after about $15 \mathrm{~min}$ by i.v. sodium pentobarbitone $(15 \mathrm{mg} / \mathrm{kg}$, Siegfried, Zofingen, Switzerland), and artificially ventilated with oxygen-enriched air using a respiratory pump (Harvard 613; Harvard Apparatus, South Natick, MA, USA). Anesthesia was maintained throughout the experiments by a continuous i.v. infusion of sodium pentobarbitone $(7 \mathrm{mg} / \mathrm{kg}$ per $\mathrm{h})$ and assessed as reported previously (Linden \& Mary 1983). Pressures in the ascending aorta and right atrium were recorded via catheters connected to pressure transducers (Statham P23 XL; Gould, Valley View, OH, USA) inserted, respectively, into the right femoral artery and right external jugular vein. The chest was opened in the left fourth intercostal space, the pericardium was cut, and an ultrasound flowmeter probe (model 420; Transonic Systems, Ithaca, NY, USA) was positioned around the proximal part of the left anterior descending (LAD) coronary artery to record coronary blood flow. Left ventricular pressure was measured using a catheter connected to a pressure transducer (Gould) inserted through the left atrium. To pace the heart, electrodes were sewn on the left atrial appendage and connected to a stimulator (model S8800; Grass Instruments, Quincy, MA, USA), which delivered pulses of $3-5 \mathrm{~V}$ for 2 -ms duration at the required frequency. To assess regional contractile function, pairs of $2 \mathrm{~mm}$ ultrasonic segment length microtransducer crystals (Sonometrics, London, ON, Canada) were implanted in the left anterior ventricular wall in the distribution area of the LAD, about $10 \mathrm{~mm}$ apart and parallel to the direction of the fibers, so that the segmental shortening (SS) was in line with the orientation

Published by Bioscientifica Ltd. 
of fibers. Two additional crystals were placed at opposite ends of the left ventricular short axis to measure changes in ventricular dimension throughout cardiac cycles (Grossini et al. 2009, 2011a,b, 2013a,b). Arterial blood samples were used to measure $\mathrm{pH}$, arterial pressure of oxygen and carbon dioxide $\left(\mathrm{PO}_{2}\right.$ and $\left.\mathrm{PCO}_{2}\right)$ with a gas analyzer (Radiometer ABL505, Copenhagen, Denmark) and the hematocrit. Sampling of blood from the LAD and the anterior interventricular vein allowed the measurement of coronary arterial and venous $\mathrm{PO}_{2}$ and arteriovenous oxygen content. Coronary venous blood samples were also taken for NO detection by Griess Reagent System (Promega) and for adiponectin confirmation by western blot analysis. The acid-base status of the animals was kept within normal limits as reported previously (Linden \& Mary 1983). Infusions into the LAD were performed using a catheter connected to a butterfly needle inserted into the coronary artery distal to the flowmeter probe. To prevent changes of arterial blood pressure, a pressurized reservoir connected to the arterial system was used as described previously (Grossini et al. 2009, 2011a,b, 2013a,b). Coagulation of the blood was avoided by i.v. injection of heparin (Parke-Davis; initial doses of $500 \mathrm{IU} / \mathrm{kg}$ and subsequent doses of $50 \mathrm{IU} / \mathrm{kg}$ for every $30 \mathrm{~min}$ ). The rectal temperature of the pigs was monitored and kept between 38 and $40{ }^{\circ} \mathrm{C}$ using an electric pad. Hemodynamic variables were monitored and recorded together with heart rate and the maximum and minimum rate of change of left ventricular systolic pressure $\left( \pm \mathrm{d} P / \mathrm{d} t_{\max }\right)$ using a micro1401 A/D converter (Cambridge Electronic Design, CED, Cambridge, UK) displayed on a personal computer and processed by using Spike2 Software (CED).
The $\mathrm{d} P / \mathrm{d} t_{\max }$ was used to define the timing of the cardiac cycle for segment length measurements with ultrasonic crystals. End-diastolic length was measured at the onset of the rapid increase in $\mathrm{d} P / \mathrm{d} t_{\max }$, and end-systolic length was measured at peak negative $\mathrm{d} P / \mathrm{d} t_{\max }$. Enddiastolic and end-systolic ventricular volumes were obtained from data of end-diastolic and end-systolic lengths through the specific software (Sonometrics). Percentage of SS (\%SS) was calculated using the following formula: $\% \mathrm{SS}=$ (end-diastolic length-end-systolic length) $\times 100$ /end-diastolic length. The data from the sonomicrometer crystals were digitally processed by specific hardware and software (Sonometrics). Cardiac output was derived using the Sonosoft System from data recorded by piezoelectric crystals. To calculate coronary vascular resistance, the difference between mean aortic blood pressure and mean left ventricular pressure during diastole was considered as the coronary pressure gradient. Coronary vascular resistance was calculated as the ratio between this pressure gradient and mean diastolic coronary blood flow during the steady state. At the end of the experiment, each animal was killed by an i.v. injection of $90 \mathrm{mg} / \mathrm{kg}$ pentobarbitone sodium.

\section{Western immunoblot (WB)}

Coronary plasma samples, prepared by centrifugation at $1650 \mathrm{~g}$ for $15 \mathrm{~min}$ at $4{ }^{\circ} \mathrm{C}$, were size-fractionated on $10 \%$ SDS-PAGE under reducing conditions and electrotransferred to immunoblot PVDF membranes (Bio-Rad). Membranes were incubated with monoclonal antiadiponectin (Adipogen, Inc., Incheon, Korea) and detected

Table 1 Changes in hemodynamic variables caused by intracoronary infusion of $30 \mathrm{pg}, 300 \mathrm{pg}, 3 \mathrm{ng}, 30 \mathrm{ng}, 300 \mathrm{ng}$, and $3 \mu \mathrm{g}$ human monomeric adiponectin for each milliliter per minute of measured coronary blood flow in 30 pigs. Data are means \pm s.D.

\begin{tabular}{l} 
Data \\
\hline$+\mathrm{d} P / \mathrm{d} t_{\max }$ \\
$-\mathrm{d} P / \mathrm{d} t_{\max }$ \\
$\mathrm{CBF}$ \\
$\mathrm{CVR}$ \\
$\mathrm{CO}$ \\
$\% \mathrm{SS}$ \\
$\mathrm{NO}$ \\
$\mathrm{PO}_{2} \mathrm{Vc}$ \\
$(\mathrm{AV}) \mathrm{O}_{2}$ \\
$\mathrm{mVO}_{2}$ \\
\hline
\end{tabular}

\begin{tabular}{c} 
Control \\
\hline $2055 \pm 127$ \\
$-1865 \pm 119$ \\
$61.4 \pm 7.5$ \\
$1.89 \pm 0.42$ \\
$5580 \pm 468$ \\
$14.5 \pm 0.7$ \\
$0.99 \pm 0.07$ \\
$19.9 \pm 1$ \\
$11.8 \pm 0.47$ \\
$7.25 \pm 0.95$
\end{tabular}

\begin{tabular}{ccc}
$\mathbf{3 0} \mathbf{~ p g}$ & & $\mathbf{3 0 0} \mathbf{~ p g}$ \\
\cline { 1 - 1 } $2213 \pm 130^{*}$ & & $2373 \pm 141^{*, \dagger}$ \\
$-1957 \pm 125^{*, \|}$ & $-2059 \pm 129^{*, \dagger}+$ \\
$67.3 \pm 8.2^{*}$ & & $71.6 \pm 8.8^{*, \dagger}$ \\
$1.78 \pm 0.4^{*}$ & & $1.68 \pm 0.4^{*, \dagger}$ \\
$5904 \pm 520^{*}$ & & $6242 \pm 567^{*, \dagger}$ \\
$15.4 \pm 0.7^{*}$ & & $16.8 \pm 0.7^{*, \dagger}$ \\
$1.073 \pm 0.08^{*}$ & & $1.25 \pm 0.08^{*, \dagger}$ \\
$20.4 \pm 0.9^{*}$ & & $20.8 \pm 0.9^{*, \dagger}$ \\
$10.7 \pm 0.49^{*}$ & & $10.1 \pm 0.54^{*, \dagger}$ \\
$7.26 \pm 0.96$ & $7.25 \pm 1$
\end{tabular}

\begin{tabular}{c}
\hline $3 \mathbf{n g}$ \\
\hline $2617 \pm 151^{*, \neq}$ \\
$-2176 \pm 131^{*, \neq}$ \\
$76 \pm 8.7^{*, \neq}$ \\
$1.55 \pm 0.38^{*, \neq}$ \\
$6449 \pm 545^{*, \neq}$ \\
$18.6 \pm 0.38^{*, \neq}$ \\
$1.58 \pm 0.11^{*, \neq}$ \\
$21.2 \pm 0.9^{*, \neq}$ \\
$9.57 \pm 0.49^{*, \neq}$ \\
$7.29 \pm 1$
\end{tabular}

\begin{tabular}{c}
\hline $\mathbf{3 0} \mathbf{n g}$ \\
\hline $2665 \pm 155^{*, \S}$ \\
$-2235 \pm 128^{*, \S}$ \\
$76.7 \pm 8.9^{*, \S}$ \\
$1.52 \pm 0.39^{*, / 1}$ \\
$6518 \pm 594^{*, \S}$ \\
$18.84 \pm 0.38^{*, \S}$ \\
$1.6 \pm 0.1^{*, \S}$ \\
$21.4 \pm 11^{*, \S}$ \\
$9.5 \pm 0.48^{*, / 1}$ \\
$7.29 \pm 1$
\end{tabular}

\begin{tabular}{c}
\hline $300 \mathbf{n g}$ \\
\hline $2671 \pm 159^{*} \pi$ \\
$-2269 \pm 135^{*}$, \\
$76.8 \pm 8.6^{*}$ \\
$1.52 \pm 0.38^{*}$ \\
$6520 \pm 598^{*}$ \\
$18.87 \pm 0.38^{*}$ ब \\
$1.6 \pm 0.1 *$ \\
$21.5 \pm 1 *$ \\
$9.48 \pm 0.47^{*}$ \\
$7.3 \pm 0.97$
\end{tabular}

\begin{tabular}{c}
\hline $\mathbf{3} \mu \mathbf{g}$ \\
\hline $2674 \pm 159^{*, a}$ \\
$-2278 \pm 134^{*, a}$ \\
$77 \pm 8.6^{*}$ \\
$1.51 \pm 0.38^{*}$ \\
$6522 \pm 597^{*}$ \\
$18.89 \pm 0.38^{*, a}$ \\
$1.6 \pm 0.1^{*}$ \\
$21.51 \pm 0.9^{*}$ \\
$9.47 \pm 0.49^{*}$ \\
$7.3 \pm 1$
\end{tabular}

$+\mathrm{d} P / \mathrm{d} t_{\text {max }}$ maximum rate of change of left ventricular systolic pressure $(\mathrm{mmHg} / \mathrm{s}) ;-\mathrm{d} P / \mathrm{d} t_{\mathrm{max}}$ minimum rate of change of left ventricular systolic pressure $(\mathrm{mmHg} / \mathrm{s}) ; \mathrm{CBF}$, mean coronary blood flow ( $\mathrm{ml} / \mathrm{min}) ; \mathrm{CVR}$, coronary vascular resistances ( $\mathrm{mmHg} / \mathrm{ml}$ per $\mathrm{min}$ ); CO, cardiac output ( $\mathrm{ml} / \mathrm{min}) ; \% S S$, percentage of segmental shortening; $\mathrm{NO}$, nitric oxide ( $\mu \mathrm{mol} / 1.5 \mu \mathrm{g}$ protein); $\mathrm{PO}_{2} \mathrm{vc}$, coronary sinus partial pressure of oxygen $(\mathrm{mmHg}) ;(\mathrm{AV}) \mathrm{O}_{2}$, coronary arteriovenous oxygen content $\left(\mathrm{ml} \mathrm{O} \mathrm{O}_{2} / 100 \mathrm{ml}\right) ; \mathrm{mVO}_{2}$, myocardial oxygen consumption $\left(\mathrm{ml} \mathrm{O} \mathrm{O}_{2} / \mathrm{min}\right.$ per $\left.100 \mathrm{~g}\right)$. $* P<0.0001$ vs control (taken before adiponectin administration at constant HR and $A B P$ ): ${ }^{\dagger} P<0.0001$ vs $30 \mathrm{pg}$ adiponectin; ${ }^{\ddagger} P<0.0001$ vs 300 pg adiponectin; ${ }^{\$} P<0.0001$ vs $3 \mathrm{ng}$ adiponectin; $P=0.01$ vs $3 \mathrm{ng}$ adiponectin; ${ }^{\top} P=0.01$ vs $30 \mathrm{ng}$ adiponectin; and ${ }^{\mathrm{a}} P=0.01$ vs $300 \mathrm{ng}$ adiponectin.

http://joe.endocrinology-journals.org DOI: $10.1530 / \mathrm{JOE}-14-0170$
() 2014 Society for Endocrinology Printed in Great Britain
Published by Bioscientifica Ltd. 
with the appropriate HRP-conjugated secondary antibody (Chemicon Millipore, Temecula, CA, USA). Immunoreactive proteins were detected using ECL (Pierce Biotechnology, Rockford, IL, USA) with image capture performed using CCD camera linked to ChemiDoc (Bio-Rad).

\section{Experimental protocol}

The experiments were begun after at least 30 min of steadystate conditions. In the 30 pigs, the effects of various doses of human monomeric adiponectin (30 kDa; Sigma) on cardiac perfusion and function were examined by infusing either human monomeric adiponectin dissolved in saline or saline only into the LAD. Each dose of adiponectin was infused over 5 min by means of an infusion pump (model 22; Harvard Apparatus, South Natick, MA, USA), working at constant rate of $1 \mathrm{ml} / \mathrm{min}$. The infused doses amounted to $30 \mathrm{pg}, 300 \mathrm{pg}, 3 \mathrm{ng}, 30 \mathrm{ng}, 300 \mathrm{ng}$, and $3 \mu \mathrm{g}$ for each milliliter per minute of measured coronary blood flow.
In these animals, the heart was paced to a frequency higher, by 20 beats/min, than that observed during the steady state and the arterial system was connected to the pressurized reservoir. Moreover, coronary artery and venous plasma samples were taken for measurement of $\mathrm{PO}_{2}$, oxygen, human monomeric adiponectin, and $\mathrm{NO}$ content.

Recordings taken for $10 \mathrm{~min}$ during the steady-state conditions before infusion of human monomeric adiponectin at constant heart rate and aortic blood pressure were used as control. Measurements of hemodynamic variables, coronary artery and coronary venous $\mathrm{PO}_{2}$, human monomeric adiponectin, arteriovenous oxygen content, and NO were obtained during the last $30 \mathrm{~s}$ of each dose infusion in the steady state and compared with control values. Myocardial oxygen consumption $\left(\mathrm{mVO}_{2} ; \mathrm{ml} \mathrm{O}_{2} / \mathrm{min}\right.$ per $\left.100 \mathrm{~g}\right)$ was calculated as the product of coronary arteriovenous oxygen content and coronary blood flow. Moreover, NO content in coronary venous blood was measured, as described previously
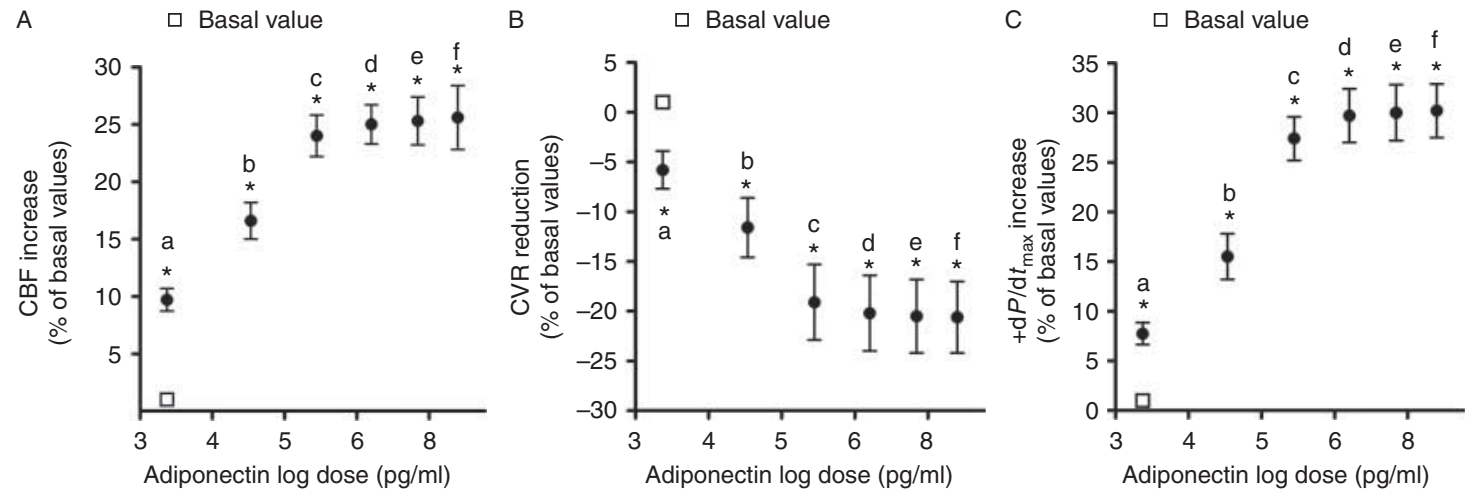

D

๑ Basal value

E

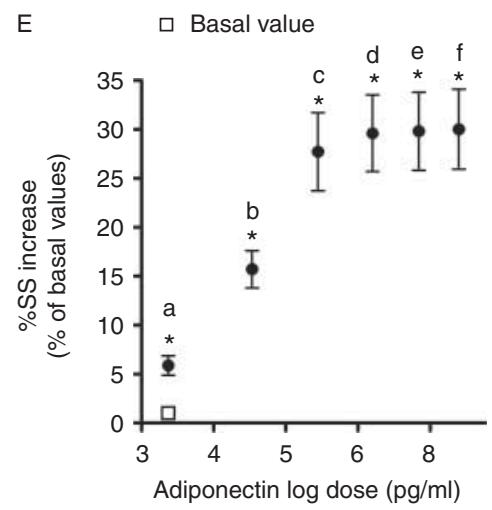

$\mathrm{F}$

Basal value
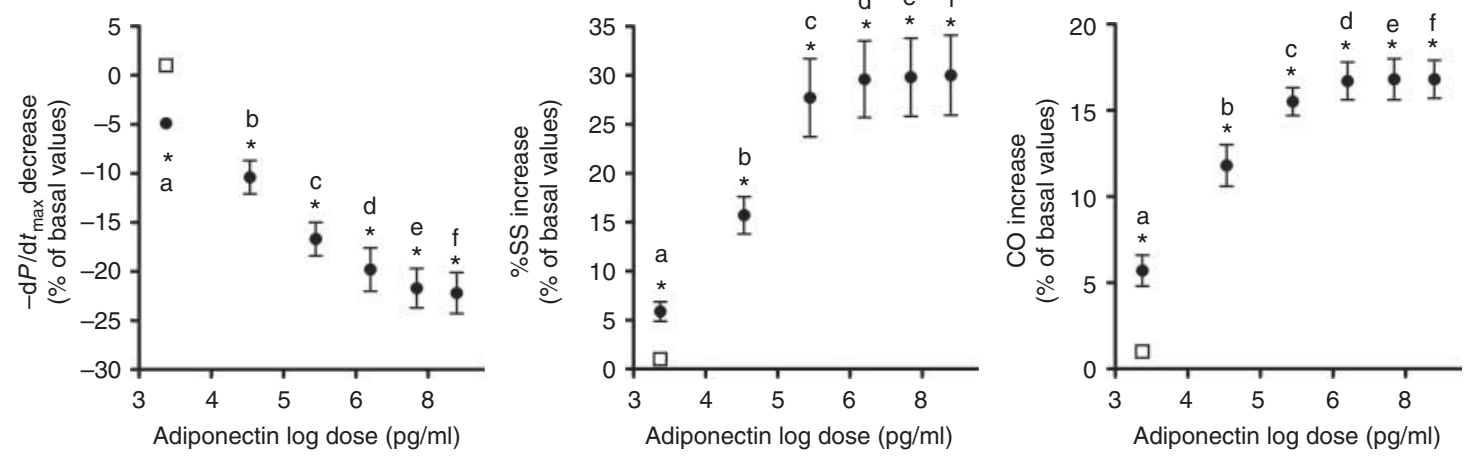

\section{Figure 1}

Effects of intracoronary infusion of human monomeric adiponectin on mean coronary blood flow (CBF; A), coronary vascular resistances (CVR; B), maximum rate of change of left systolic ventricular pressure $\left(+\mathrm{d} P / \mathrm{d} t_{\text {max }} ; \mathrm{C}\right)$, minimum rate of change of left systolic ventricular pressure $\left(-\mathrm{d} P / \mathrm{d} t_{\max } ; \mathrm{D}\right)$, percentage of segmental shortening (\%SS; E), and cardiac output (CO; F) in 30 pigs. The means of percentage changes in hemodynamic parameters obtained in the 30 pigs during the test period of measurement are plotted against the logarithm of doses of adiponectin from $30 \mathrm{pg}$ to $3 \mu \mathrm{g}$ for each milliliter per minute of measured coronary blood flow. The continuous line is the line of equality. The bars indicate s.D. ${ }^{*} P<0.05$ vs basal value; (b, $c, d, e$ and f), $P<0.05$ vs (a); (c, d, e and f), $P<0.05$ vs (b); (d, e and f), $P<0.05$ vs (c); in (C), (D) and (E): (e and f), $P<0.05$ vs (d); and (f), $P<0.05$ vs (e). 
(Grossini et al. 2009, 2011a,b, 2013a,b), following the same time course followed for $\mathrm{PO}_{2}$ and oxygen content measurement, and values were compared with those of control.

In the pigs, the role of muscarinic cholinoceptors and $\alpha$ - and $\beta$-adrenoceptors was examined throughout by repeating $3 \mu \mathrm{g}$ for each milliliter per minute of measured coronary blood human monomeric adiponectin administration after the i.v. administration of muscarinic cholinoceptors blocker, atropine sulfate $(0.5 \mathrm{mg} / \mathrm{kg}$, Sigma, $n=5), \alpha$-adrenoceptor blocker, phentolamine $(1 \mathrm{mg} / \mathrm{kg}$, Sigma, $n=5), \beta_{1}$-adrenoceptor blocker, atenolol $(1 \mathrm{mg} / \mathrm{kg}$, Sigma, $n=5)$, and $\beta_{2}$-adrenoceptor blocker, butoxamine $(2.5 \mathrm{mg} / \mathrm{kg}$, Sigma, $n=5)$. The involvement of NOS and AdipoR1 was examined, respectively, by repeating human monomeric adiponectin infusion after intracoronary administration of the NOS inhibitor N $\omega$-nitro-L-arginine methyl ester (L-NAME; $2 \mathrm{mg}$ for each milliliter per minute of measured coronary blood flow, Sigma, $n=5$ ), and $3 \mu \mathrm{g}$ for each milliliter per minute of measured coronary blood GTX89569-PEP (GeneTex, Irvine, CA, USA, $n=5$ ). The effect of blocking agents and human monomeric adiponectin on NO release, coronary artery and coronary venous $\mathrm{PO}_{2}$, and myocardial oxygen consumption was examined by repeating the measurements after each blocker or adiponectin infusion in the steady state and comparing the values with those taken immediately beforehand.

All drugs were given without pacing the heart or controlling aortic pressure to assess their effects on baseline hemodynamic variables in the steady state. Thereafter, heart rate and aortic blood pressure were kept constant, and measured hemodynamic variables were taken as 'control'. In all subsequent experiments, the effects of human monomeric adiponectin in the presence of blocking agents were examined while preventing changes in heart rate and aortic blood pressure. Changes of hemodynamic variables caused by various agents were compared with control values.

\section{Statistical analyses}

All data were recorded using the Institution's database. Statistical analysis was performed by using STATVIEW, version 5.0.1 for Microsoft Windows (SAS Institute, Cary, NC, USA). Data were checked for normality before statistical analysis. Student's paired $t$-test was used to examine changes of measured variables within each animal before and after any treatment. One-way ANOVA followed by Bonferroni's post-hoc test was used to compare differences among groups of animals. Nonparametric Wilcoxon's signed-rank test was used to compare significance of percent changes before and after blockers. Pearson's correlation coefficient was used for linear regression analysis in the dose-dependent studies. All data are presented as means \pm s.D. A value of $P<0.05$ was considered statistically significant.
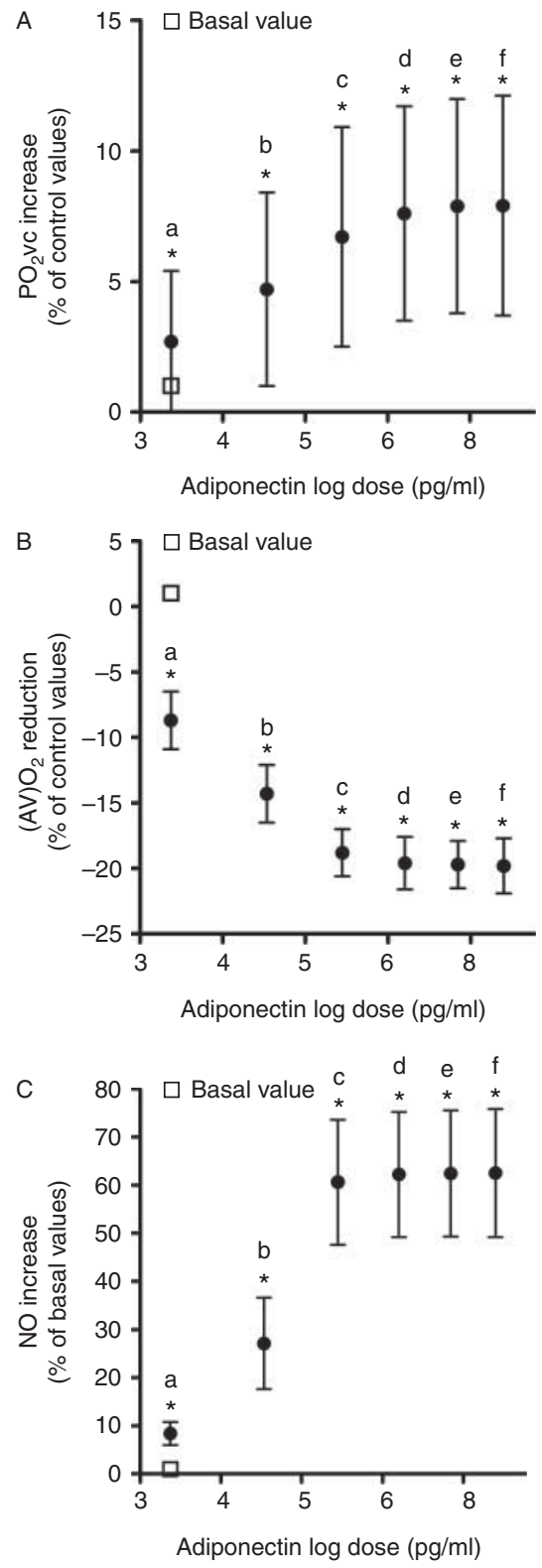

Figure 2

Effects of intracoronary infusion of human monomeric adiponectin on coronary venous $\mathrm{PO}_{2}\left(\mathrm{pO}_{2} \mathrm{vc} ; \mathrm{A}\right)$, coronary arteriovenous oxygen content $\left((\mathrm{AV}) \mathrm{O}_{2} ; \mathrm{B}\right)$, and coronary nitric oxide $(\mathrm{NO} ; \mathrm{C})$ in 30 pigs. The means of percentage changes in hemodynamic parameters obtained in the 30 pigs during the test period of measurement are plotted against the logarithm of doses of adiponectin from $30 \mathrm{pg}$ to $3 \mu \mathrm{g}$ for each milliliter per minute of measured coronary blood flow. The continuous line is the line of equality. The bars indicate s.D. ${ }^{*} P<0.05$ vs basal value; ( $b, c, d$, e and $\left.f\right), P<0.05$ vs (a); (c, d, e and f), $P<0.05$ vs (b); and (d, e and f), $P<0.05$ vs (c). 


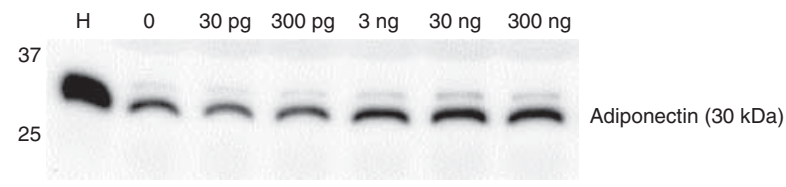

Figure 3

Western blot analysis of coronary plasma human monomeric adiponectin during various doses of human monomeric adiponectin infusion in one of the 30 pigs. $\mathrm{H}$, human and 0 , before human monomeric adiponectin infusion.

\section{Results}

Dose-related effects of intracoronary human monomeric adiponectin on hemodynamic variables, NO release, and myocardial oxygen metabolism

In all pigs, recordings commenced $\sim 5 \mathrm{~h}$ after induction of anesthesia. The mean $\mathrm{pH}, \mathrm{PO}_{2}$, and $\mathrm{PCO}_{2}$ of arterial blood were $7.39 \pm 0.01(7.39-7.43), 119 \pm 11.5(100-138) \mathrm{mmHg}$, and $40 \pm 1(39-42) \mathrm{mmHg}$ and the hematocrit was $39.1 \pm 1 \%(39-41)$.

The heart rate, aortic blood pressure, right atrial pressure, and left ventricular end-diastolic pressure taken while preventing changes in heart rate and aortic blood pressure in the 30 pigs, respectively, amounted to $96.8 \pm 4.7$ beats $/ \mathrm{min}, 100.28 \pm 8.9,2.5 \pm 0.3$, and $4.7 \pm 0.7 \mathrm{mmHg}$. These values were taken as 'control'.

Intracoronary infusion of human monomeric adiponectin caused a dose-related increase in mean coronary blood flow, $+\mathrm{d} P / \mathrm{d} t_{\max }$, cardiac output, and \%SS and an improvement of $-\mathrm{d} P / \mathrm{d} t_{\max }$ (Table 1 and Fig. 1; Pearson's correlation coefficients: $0.87,0.88,0.86,0.87$, and -0.95$)$. The increase in coronary blood flow was accompanied by a decrease of coronary vascular resistances and by an increase of NO release (Table 1, Figs 1 and 2; Pearson's correlation coefficients: -0.88 and 0.85 ). Moreover, a dose-related increase of coronary venous $\mathrm{PO}_{2}$ and a reduction of arteriovenous oxygen content were found (Pearson's correlation coefficients: 0.82 and -0.86 ), in the absence of significant changes in myocardial oxygen consumption (Table 1 and Fig. 2).

Finally, analysis by WB was able to detect a dosedependent increase in human monomeric adiponectin from the coronary plasma taken in pigs (Fig. 3).

The effects of various doses of human monomeric adiponectin began within about $30 \mathrm{~s}$ after starting each dose and reached a steady state in about $2 \mathrm{~min}$ at each dose (Fig. 4). The effects of the last dose of adiponectin were almost abolished at $10 \mathrm{~min}$ after the end of administration. The intracoronary infusion of the vehicle did not affect hemodynamic variables. In addition, no changes in other hemodynamic variables were observed during adiponectin infusion.

\section{Mechanisms of the responses}

Tables 2 and 3 show the effects of the blocking agents and human monomeric adiponectin given after the blocking agents on hemodynamic variables. In Table 3 , coronary venous $\mathrm{PO}_{2}$, arteriovenous oxygen content, and myocardial oxygen consumption before and after butoxamine, L-NAME, GTX89569-PEP followed by adiponectin given in animals treated with the above agents are reported as well.

In the 15 pigs, blockade of muscarinic cholinoceptors $(n=5), \alpha$-adrenoceptors $(n=5)$, and $\beta_{1}$ adrenoceptors $(n=5)$ did not affect either the coronary and cardiac responses or the NO release caused by the intracoronary infusion of human monomeric adiponectin (Table 2 and Fig. 5).

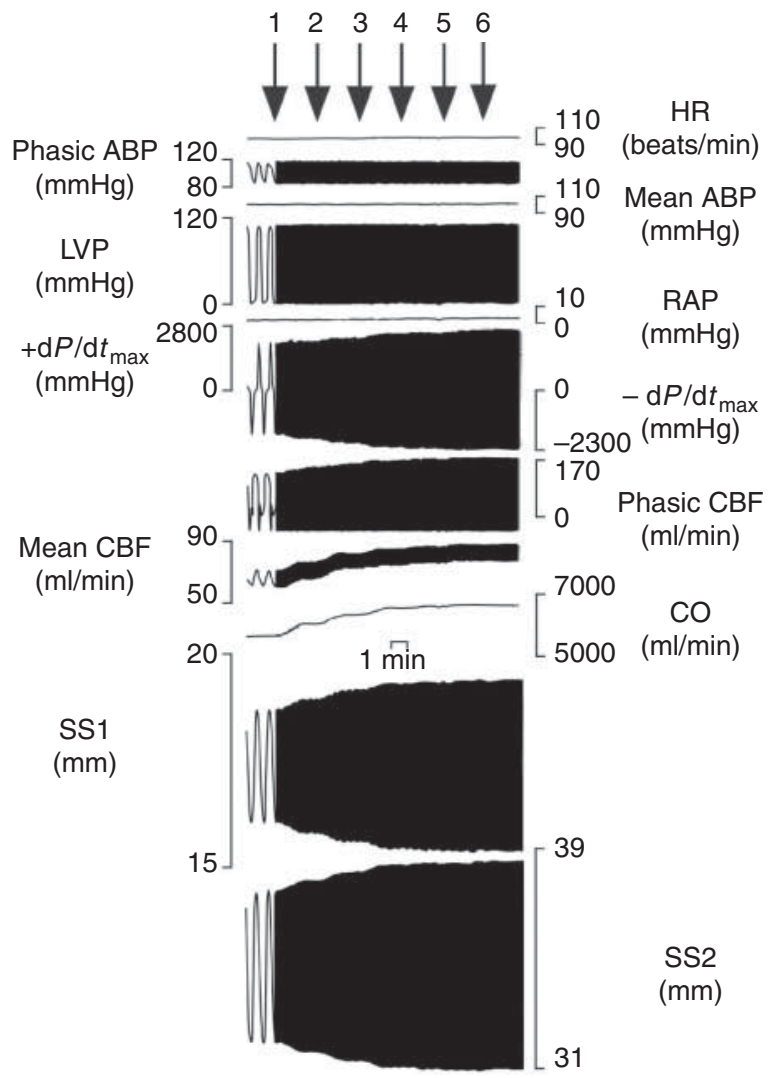

Figure 4

Example of experimental recording taken in one of the 30 pigs. From top to bottom are shown heart rate (HR), phasic and mean aortic blood pressure $(A B P)$, left ventricular pressure (LVP), right atrial pressure (RAP), $\pm \mathrm{d} P / \mathrm{d} t_{\text {max }}$ phasic and mean CBF, CO, and segment length (SL1 and SL2). The other abbreviations are as in Fig. 1. The arrow indicates the start of various doses of human monomeric adiponectin infusion (1, $30 \mathrm{pg} ; 2,300 \mathrm{pg} ; 3,3 \mathrm{ng} ; 4$, $30 \mathrm{ng} ; 5,300 \mathrm{ng}$; and 6, $3 \mu \mathrm{g}$ ).

Published by Bioscientifica Ltd. 
Table 2 Effect of human monomeric adiponectin on hemodynamic variables after blockade of muscarinic cholinoceptors and $\alpha$ - and $\beta_{1}$-adrenoceptors at constant HR and ABP. Data are means \pm s.D. Baseline, hemodynamic variables without keeping heart rate and aortic blood pressure constant. Blocking agent, effects of various agents on hemodynamic variables. Control, hemodynamic variables after blocking agents, at constant heart rate and aortic blood pressure. Adiponectin, effects of $3 \mu \mathrm{g}$ human monomeric adiponectin given after blocking agents at heart rate and aortic blood pressure constant

Data
Atropine
HR (beats/min)
ABP $(\mathrm{mmHg})$
CBF $(\mathrm{ml} / \mathrm{min})$
$+\mathrm{d} P / \mathrm{d} t_{\max }(\mathrm{mmHg} / \mathrm{s})$
$-\mathrm{d} P / \mathrm{d} t_{\max }(\mathrm{mmHg} / \mathrm{s})$
CO $(\mathrm{ml} / \mathrm{min})$
$\% \mathrm{SS}$
Phentolamine
$\mathrm{HR}(\mathrm{beats} / \mathrm{min})$
ABP $(\mathrm{mmHg})$
$\mathrm{CBF}(\mathrm{ml} / \mathrm{min})$
$+\mathrm{d} P / \mathrm{d} t_{\max }(\mathrm{mmHg} / \mathrm{s})$
$-\mathrm{d} P / \mathrm{d} t_{\max }(\mathrm{mmHg} / \mathrm{s})$
$\mathrm{CO}(\mathrm{ml} / \mathrm{min})$
$\% \mathrm{SS}$
Atenolol
$\mathrm{HR}(\mathrm{beats} / \mathrm{min})$
ABP $(\mathrm{mmHg})$
$\mathrm{CBF}(\mathrm{ml} / \mathrm{min})$
$+\mathrm{d} P / \mathrm{d} t_{\max }(\mathrm{mmHg} / \mathrm{s})$
$-\mathrm{d} P / \mathrm{d} t_{\max }(\mathrm{mmHg} / \mathrm{s})$
CO $(\mathrm{ml} / \mathrm{min})$
$\% \mathrm{SS}$

Baseline

$75.2 \pm 4.7$
$99.8 \pm 2.5$
$56.2 \pm 10.6$
$1735 \pm 104$
$-1927 \pm 83$
$4200 \pm 369$
$14.34 \pm 1.04$
$74.4 \pm 2.9$
$90 \pm 8.6$
$48.8 \pm 4.2$
$1622 \pm 36$
$-1946 \pm 156$
$4048 \pm 357$
$13.66 \pm 0.7$
$78.6 \pm 7.4$
$97.4 \pm 9.1$
$52.4 \pm 6.7$
$1673 \pm 90$
$-1998 \pm 98$
$4258 \pm 665$
$13.88 \pm 0.65$

\begin{tabular}{c}
\hline Blocking agent \\
\\
$85 \pm 4.4^{*}$ \\
$100 \pm 2.5$ \\
$57 \pm 10.8^{P=0.01}$ \\
$1968 \pm 107^{\dagger}$ \\
$-1872 \pm 83^{\dagger}$ \\
$4672 \pm 322^{P=0.01}$ \\
$14.44 \pm 0.4^{P=0.03}$ \\
$84.6 \pm 3.2^{*}$ \\
$81.4 \pm 8.2^{*}$ \\
$47.8 \pm 4.6$ \\
$1623 \pm 36.6$ \\
$-1822 \pm 156^{P=0.002}$ \\
$4062 \pm 400$ \\
$13.7 \pm 0.66$ \\
$69.2 \pm 7.2^{*}$ \\
$92 \pm 9.4^{*}$ \\
$49.2 \pm 6.7^{*}$ \\
$1350 \pm 107^{*}$ \\
$-2068 \pm 102^{\dagger}$ \\
$3370 \pm 659^{*}$ \\
$12.76 \pm 0.65^{*}$ \\
\end{tabular}

Control

$104.6 \pm 4.4$
$100.4 \pm 2.6$
$67.8 \pm 12$
$2345 \pm 119$
$-1766 \pm 83$
$6131 \pm 368$
$14.94 \pm 0.38$
$105 \pm 3.8$
$82 \pm 7.8$
$58 \pm 5.5$
$2051 \pm 50$
$-1764 \pm 153$
$5086 \pm 575$
$14.1 \pm 0.7$
$89.2 \pm 7$
$92.6 \pm 9.5$
$58.6 \pm 6.4$
$1688 \pm 111$
$-1932 \pm 110$
$4710 \pm 758$
$13.24 \pm 0.6$

\begin{tabular}{c}
\hline Adiponectin \\
\\
$104.8 \pm 4.7$ \\
$100.6 \pm 2.7$ \\
$83.6 \pm 13.6^{*}$ \\
$3003 \pm 81^{*}$ \\
$-2131 \pm 137^{*}$ \\
$7148 \pm 283^{*}$ \\
$19.1 \pm 0.5^{*}$ \\
$105.2 \pm 3.7$ \\
$82.2 \pm 8.5$ \\
$72.2 \pm 6.5^{*}$ \\
$2588 \pm 108^{*}$ \\
$-2068 \pm 146^{*}$ \\
$5898 \pm 615^{*}$ \\
$18.36 \pm 0.2^{\dagger}$ \\
$89.4 \pm 7.3$ \\
$93 \pm 9$ \\
$72 \pm 6.9^{*}$ \\
$2120 \pm 133^{*}$ \\
$-2365 \pm 146^{*}$ \\
$5400 \pm 766^{*}$ \\
$16.9 \pm 0.5^{*}$
\end{tabular}

$\mathrm{HR}$, heart rate; $\mathrm{ABP}$, mean aortic blood pressure; $\mathrm{CBF}$, mean coronary blood flow; $+\mathrm{d} P / \mathrm{d} t_{\text {max }}$, maximum rate of change of left ventricular systolic pressure; $-\mathrm{d} P / \mathrm{d} t_{\max }$ minimum rate of change of left ventricular systolic pressure; $\mathrm{CO}$, cardiac output; \%SS, percentage of segmental shortening. ${ }^{\star} P<0.0001$ vs baseline or control. ${ }^{\dagger} P<0.002$ vs baseline or control.

In pigs treated with $\beta_{2}$-adrenoceptor blocker $(n=5)$ and NOS inhibitor $(n=5)$, the effects of human monomeric adiponectin on coronary blood flow and NO release were abolished in the absence of significant changes of responses of cardiac function (Table 3 and Fig. 5). In addition, changes in myocardial oxygen metabolism were not significant (Fig. 6).

It is notable that the administration of GTX89569-PEP $(n=5)$ caused a reduction of basal $\pm \mathrm{d} P / \mathrm{d} t_{\max }$ and coronary blood flow (Table 3). In addition, the AdipoR1 blocker completely prevented the effects of human monomeric adiponectin on both cardiac function and perfusion and coronary venous $\mathrm{PO}_{2}$ and coronary arteriovenous oxygen content (Figs 5 and 6).

\section{Discussion}

This is the first study showing the direct effects of human monomeric adiponectin on myocardial perfusion and function through the involvement of AdipoR1 and $\beta_{2}$-adrenoceptor-related NO release in anesthetized pigs.
Adiponectin, an adipokine predominantly secreted from adipose tissue, exerts multiple protective properties against obesity, insulin resistance (Lau et al. 2011), and cardiovascular diseases (Hui et al. 2012). Adiponectin circulates in plasma as homo-oligomers, trimer, hexamer, and high-molecular-weight (HMW) forms, as well as a truncated form corresponding to the globular domain.

The results of the present study have shown for the first time that intracoronary human monomeric adiponectin infusion in anesthetized pigs acutely increased myocardial perfusion and improved systolic and diastolic ventricular function in a dose-dependent way. It is noteworthy that those results were obtained by human monomeric adiponectin infusion starting from a very low dose up to doses similar to the ones reported for circulating adiponectin, which range from 0.5 to $30 \mu \mathrm{g} / \mathrm{ml}$ (Lau et al. 2011). Moreover, the infusion of such doses of adiponectin was found to result in a doserelated increase of coronary plasma human monomeric adiponectin levels. 
Table 3 Effect of human monomeric adiponectin on hemodynamic variables after blockade of $\beta_{2}$-adrenoceptors, NOS, and subtype 1 adiponectin receptors at constant HR and ABP. Data are means \pm s.D.

\begin{tabular}{l} 
Data \\
\hline Butoxamine \\
HR (beats/min) \\
ABP $(\mathrm{mmHg})$ \\
CBF $(\mathrm{ml} / \mathrm{min})$ \\
$+\mathrm{d} P / \mathrm{d} t_{\max }(\mathrm{mmHg} / \mathrm{s})$ \\
$-\mathrm{d} P / \mathrm{d} t_{\max }(\mathrm{mmHg} / \mathrm{s})$ \\
$\mathrm{CO}(\mathrm{ml} / \min )$ \\
$\% \mathrm{SS}$ \\
L-NAME \\
$\mathrm{HR}(\mathrm{beats} / \mathrm{min})$ \\
ABP $(\mathrm{mmHg})$ \\
$\mathrm{CBF}(\mathrm{ml} / \mathrm{min})$ \\
$+\mathrm{d} P / \mathrm{d} t_{\max }(\mathrm{mmHg} / \mathrm{s})$ \\
$-\mathrm{d} P / \mathrm{d} t_{\max }(\mathrm{mmHg} / \mathrm{s})$ \\
$\mathrm{CO}(\mathrm{ml} / \mathrm{min})$ \\
$\% \mathrm{SS}$ \\
$\mathrm{GTX} 89569$ \\
$\mathrm{HR}(\mathrm{beats} / \mathrm{min})$ \\
ABP $(\mathrm{mmHg})$ \\
$\mathrm{CBF}(\mathrm{ml} / \mathrm{min})$ \\
$+\mathrm{d} P / \mathrm{d} t_{\max }(\mathrm{mmHg} / \mathrm{s})$ \\
$-\mathrm{d} P / \mathrm{d} t_{\max }(\mathrm{mmHg} / \mathrm{s})$ \\
$\mathrm{CO}(\mathrm{ml} / \mathrm{min})$ \\
$\% \mathrm{SS}$
\end{tabular}

Baseline
$76 \pm 7.2$
$99 \pm 11.3$
$53.2 \pm 8.7$
$1703 \pm 165$
$-1922 \pm 26$
$4346 \pm 707$
$14 \pm 1.1$
$74 \pm 1.6$
$105 \pm 3.7$
$52.8 \pm 3.5$
$1769 \pm 102$
$-2037 \pm 22$
$4262 \pm 383$
$14.58 \pm 0.3$
$77 \pm 3.4$
$100 \pm 3.3$
$48.4 \pm 2.4$
$1691 \pm 78$
$-1905 \pm 185$
$4056 \pm 169$
$14 \pm 0.2$

\begin{tabular}{c}
\hline Blocking agent \\
\hline $70.4 \pm 7.6^{*}$ \\
$105 \pm 11.6^{*}$ \\
$48.6 \pm 8.5^{*}$ \\
$1703 \pm 163$ \\
$-1961 \pm 23$ \\
$4346 \pm 659$ \\
$14 \pm 1.1$ \\
$69 \pm 1.6^{P=0.0002}$ \\
$114.2 \pm 3.7^{*}$ \\
$52.6 \pm 5.1$ \\
$1771 \pm 98$ \\
$-1990 \pm 16$ \\
$4237 \pm 197$ \\
$14.62 \pm 0.3$ \\
$77 \pm 4.4$ \\
$100 \pm 2.2$ \\
$45.6 \pm 2.5^{P=0.001}$ \\
$1491 \pm 79^{P=0.0003}$ \\
$-1652 \pm 128^{P=0.002}$ \\
$3878 \pm 141^{P=0.001}$ \\
$13.6 \pm 0.19^{P=0.002}$
\end{tabular}

Control

$90.4 \pm 7.6$
$106 \pm 11.5$
$57.2 \pm 9.3$
$2077 \pm 209$
$-1872 \pm 19$
$5394 \pm 672$
$14.56 \pm 1.1$
$89 \pm 1.4$
$114.6 \pm 4$
$63.2 \pm 5.1$
$2113 \pm 98$
$-1872 \pm 39$
$5554 \pm 162$
$15 \pm 0.3$
$97 \pm 4.4$
$101 \pm 1.9$
$54.6 \pm 2.7$
$1843 \pm 59$
$-1592 \pm 131$
$4807 \pm 172$
$14 \pm 0.18$

\begin{tabular}{c} 
Adiponectin \\
\hline \\
$90.6 \pm 7.5$ \\
$106 \pm 11.3$ \\
$57 \pm 9.5$ \\
$2635 \pm 205^{*}$ \\
$-2310 \pm 20^{*}$ \\
$6300 \pm 738^{P=0.0001}$ \\
$18.46 \pm 0.9 *$ \\
$89.2 \pm 1.6$ \\
$114.4 \pm 4$ \\
$63.2 \pm 5$ \\
$2693 \pm 85^{*}$ \\
$-2254 \pm 81^{*}$ \\
$6441 \pm 236 *$ \\
$18.78 \pm 0.1 *$ \\
\\
$97.4 \pm 4.6$ \\
$100.6 \pm 2$ \\
$54.4 \pm 2.9$ \\
$1847 \pm 55$ \\
$-1598 \pm 124$ \\
$4810 \pm 185$ \\
$14 \pm 0.19$
\end{tabular}

GTX89569, subtype 1 adiponectin receptor blocker. Layout and other abbreviations are as in Table $2 .{ }^{\star} P<0.0001$ vs baseline or control.

Since the experiments were carried out while preventing changes in heart rate and arterial blood pressure and in the absence of changes in cardiac filling pressures, the observed responses represented the primary effects of human monomeric adiponectin on the coronary circulation and cardiac function. Furthermore, none of those responses to adiponectin could be obtained during intracoronary infusion of the vehicle alone given at the same rate as that of the peptide. In addition, the above effects were accompanied by a significant increase of coronary venous $\mathrm{PO}_{2}$ and a decrease of arteriovenous sinus oxygen content, which could be related to the increased coronary blood flow caused by adiponectin (Tune et al. 2004).

It is notable that to date, knowledge of the exact role of adiponectin in cardiac function has been confusing and conflicting. While it may be accepted that adiponectin could be involved in the pathophysiology of heart disease, it is not so clear if it acts as a positive or negative modulator. On the one hand, the association of 'hyperadiponectinemia' with increased mortality risk was found to be more pronounced in patients with cardiovascular disease than in those without so that the expected cardioprotective effect fails to materialize
(Hui et al. 2012). The observed paradoxical increase in adiponectin has been hypothesized to be either a kind of modulatory response of inflamed tissue to counter the atherosclerotic process or the consequence of 'adiponectin resistance' of tissues (Bidulescu et al. 2013). On the other hand, circulating adiponectin in type 2 diabetic patients has been reported to be lower in the presence of coronary artery disease, and clinical observations have demonstrated that plasma adiponectin levels obtained after myocardial infarction correlate positively with myocardial salvage index and ejection fraction recovery (Shibata et al. 2008). As such, reduced adiponectin production has been recognized as a risk factor of cardiovascular disease.

The results obtained in the present study are in agreement with the latter observations and with those taken in adiponectin knock-out mice and in anesthetized pigs with myocardial ischemia/reperfusion injury, in which adiponectin was able to exert protective effects on cardiac function (Shibata et al. 2005, Tao et al. 2007, Kondo et al. 2010). In addition, our findings on ventricular relaxation are in line with those taken in patients showing an association between low plasma adiponectin and a worsened diastolic dysfunction (Negi et al. 2012). 
A

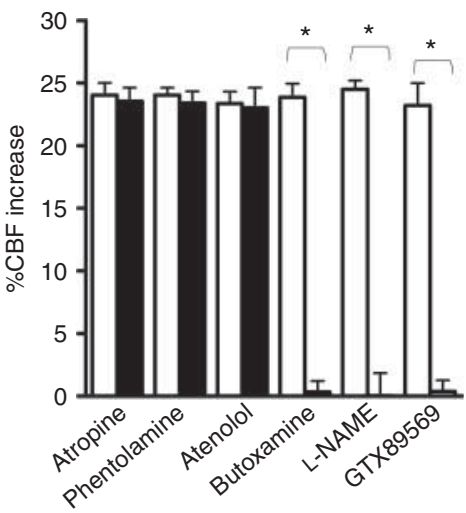

D

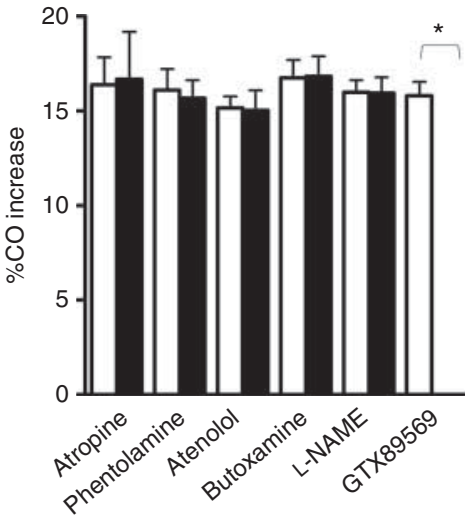

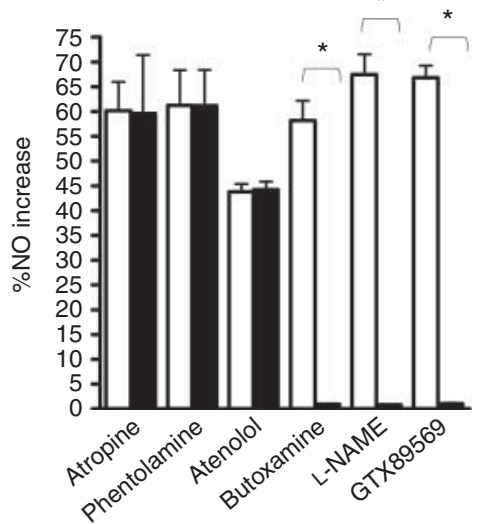

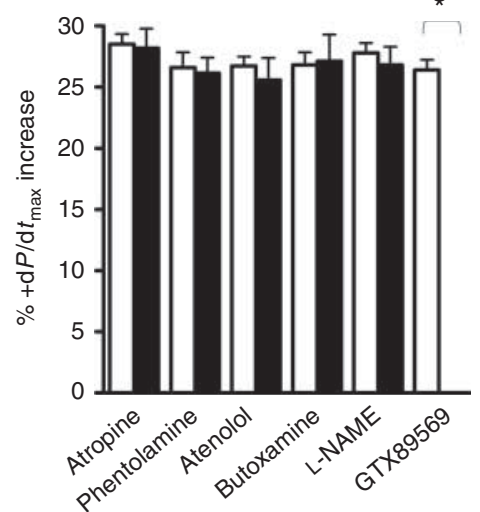

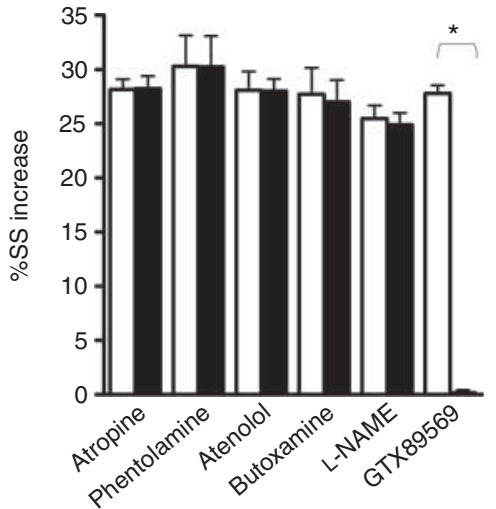

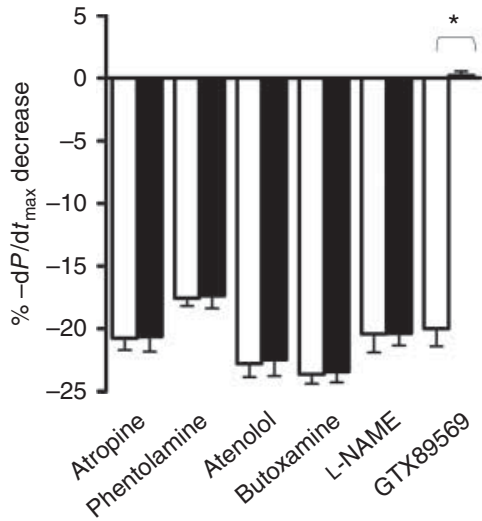

Figure 5

Effects of intracoronary infusion of human monomeric adiponectin on CBF (A), nitric oxide (NO; B), \%SS (C), CO (D), $+\mathrm{dP} / \mathrm{d} t_{\max }(\mathrm{E}),-\mathrm{d} P / \mathrm{d} t_{\max }$ (F) before and after blockade of muscarinic cholinoreceptors $(n=5)$, $\alpha$-adrenoceptors $(n=5), \beta_{1}$-adrenoceptors $(n=5), \beta_{2}$-adrenoceptors $(n=5)$, the NO synthase $(n=5)$, and subtype 1 of adiponectin receptors $(n=5)$.

The results obtained about $-\mathrm{d} P / \mathrm{d} t_{\max }$ and those regarding myocardial oxygen metabolism are of particular relevance and strengthen the role of human monomeric adiponectin as a beneficial modulator of the cardiovascular system. It is to note that our findings on myocardial oxygen consumption are novel and are in disagreement with previous observations where the beneficial metabolic effects elicited by adiponectin were accompanied by an increase of $\mathrm{mVO}_{2}$ (Fang et al. 2010). Differences in experimental protocol and setup could explain that discrepancy. Hence, in that study primary cardiomyocytes and isolated working perfused hearts were used, which is a quite different condition from the in vivo experimental setup. It is also to note that those tissues were taken from rats and mice and not from pigs. Moreover, full-length adiponectin instead of
Adiponectin was infused before (open columns) and after (filled columns) giving atropine, phentolamine, atenolol, butoxamine, L-NAME, and GTX89569. Abbreviations are the same as previous figures. The bars indicate S.D. ${ }^{*} P<0.0001$.

monomeric adiponectin was tested for $60 \mathrm{~min}$ at higher concentration $(4 \mu \mathrm{g} / \mathrm{ml})$ than those used in the present study. Finally, in cardiomyocytes the effects of adiponectin on metabolism and oxygen consumption were found to be related to APPL1, an adaptor protein containing a pleckstrin homology domain, a phosphotyrosine binding domain, and a leucine zipper motif, which is a direct interacting partner of both AdipoR1 and AdipoR2 (Mao et al. 2006). However, in addition to APPL1, several other signaling molecules, such as receptor for activated protein kinase C1 (RACK1), the regulatory subunit of protein kinase CK2 (CK2 $\beta)$, endoplasmic reticulum protein 46 (ERp46), and lymphotoxin- $\beta$, have been identified as interacting partners of AdipoR1 and intracellular mediators of the response to adiponectin. Thus, the discrepancy found about $\mathrm{mVO}_{2}$ could also rely on 

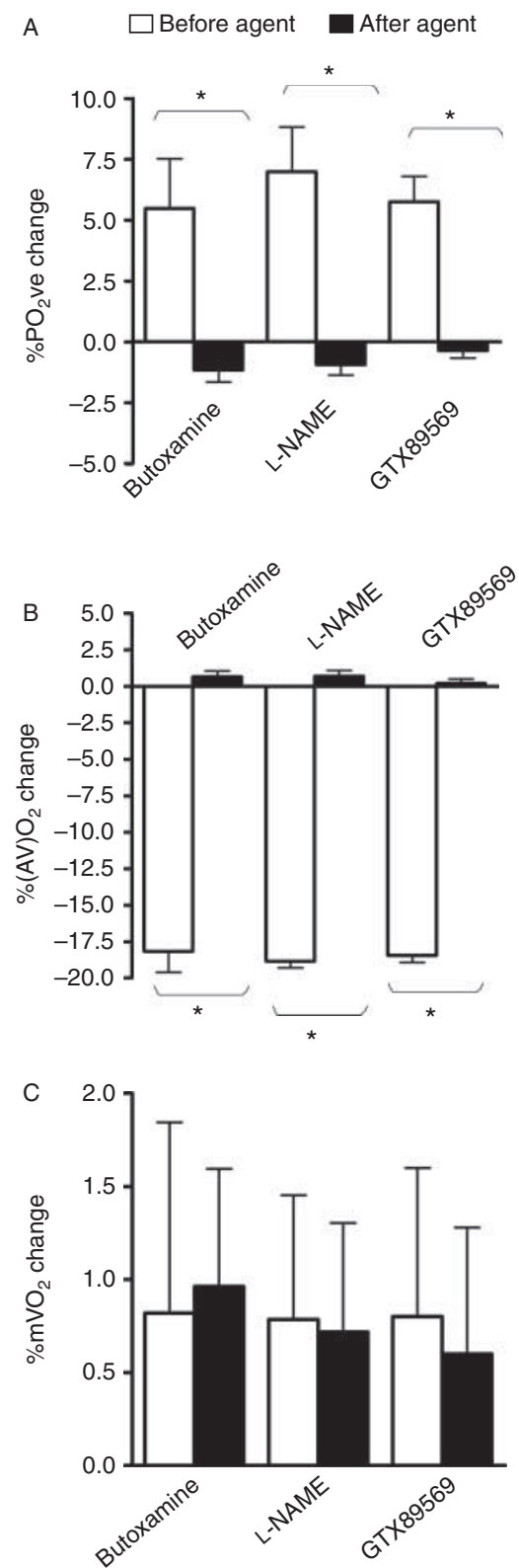

\section{Figure 6}

Effects of intracoronary infusion of human monomeric adiponectin on coronary venous $\mathrm{PO}_{2}\left(\mathrm{pO}_{2} \mathrm{vc} ; \mathrm{A}\right)$, coronary arteriovenous oxygen content $\left((\mathrm{AV}) \mathrm{O}_{2} ; \mathrm{B}\right)$ and myocardial oxygen consumption $\left(\mathrm{mVO}_{2} ; \mathrm{C}\right)$ before and after blockade of $\beta_{2}$-adrenoceptors $(n=5)$, the NO synthase $(n=5)$, and subtype 1 of adiponectin receptors $(n=5)$. Adiponectin was infused before (open columns) and after (filled columns) giving butoxamine, L-NAME, and GTX89569. Abbreviations are the same as previous figures. The bars indicate S.D. ${ }^{*} P<0.0001$.

different intracellular pathways activated by adiponectin in different animal species.

In the same controlled anesthetized animals, the administration of atropine, phentolamine, atenolol, butoxamine, and L-NAME, infused at the same doses as the ones previously used (Grossini et al. 2009, 2011a,b, $2013 a, b)$, was applied to examine the involvement of muscarinic cholinoceptors, $\alpha-, \beta_{1^{-}}, \beta_{2^{-}}$-adrenoceptors, and NOS on the cardiovascular effects elicited by human monomeric adiponectin. Neither the blockade of muscarinic cholinoceptors nor the administration of phentolamine or atenolol affected the hemodynamic responses to adiponectin, indicating that the above effects did not involve muscarinic cholinoceptors or $\beta_{1}$-adrenoceptors.

In contrast, the results obtained after butoxamine and L-NAME administration showed the involvement of both $\beta_{2}$-adrenoceptors and $\mathrm{NO}$ on coronary effects elicited by local human monomeric adiponectin infusion, in that the coronary response was abolished by both agents. The idea that NO could play a role in the coronary response to adiponectin was also supported by plasma NO measurement, which was performed by the Griess method as described previously (Grossini et al. 2009, 2011a,b, $2013 a, b)$. Hence, for the first time, intracoronary human monomeric adiponectin was found to increase NO release in a dose-dependent way. Taken together, these results highlight the role of human monomeric adiponectin as an agent that can cause endothelium-dependent vasodilation in the coronary vasculature and are in agreement with previous findings about the regulation of vascular tone elicited by adiponectin in various regions (Fesus et al. 2007, Bussey et al. 2011) and NO release in endothelial cells (Cheng et al. 2007) or ischemic-reperfused tissue (Tao et al. 2007). Moreover, as reported previously, the observed NO release may contribute to the cardiovascular protective effects elicited by adiponectin in physiological conditions (Ignarro 1989).

Furthermore, the present observations regarding the involvement of $\beta_{2}$-adrenoceptors in the coronary response to human monomeric adiponectin are new findings and confirm previous data on this issue. Hence, $\beta_{2}$-adrenoceptor excitation has been reported to increase cellular uptake of L-arginine and eNOS activity in human endothelial cells (Conti et al. 2013). Moreover, the involvement of $\beta_{2}$-adrenoceptor-related $\mathrm{NO}$ release has been found to play a role in the coronary effects of other agents intracoronary infused in the same animal model (Grossini et al. 2009, 2011a,b, 2013a,b). Information about the relationship between $\beta$-adrenoceptors and adiponectin has been scarce and only concerned the modulation of adiponectin gene expression in adipose tissue, which has been found to be inhibited by $\beta$-adrenergic stimulation (Fasshauer et al. 2001). When those observations are taken together, despite being obtained in a different context, they would support the

Published by Bioscientifica Ltd. 
existence of a type of feedback regulation between adiponectin and $\beta$-adrenoceptors. Future studies are necessary to better address this issue.

Globular and full-length adiponectin are widely reported to exert their effects through interaction with two distinct AdipoRs, AdipoR1 and AdipoR2, which are highly related and share about $80 \%$ sequence identity (Yamauchi et al. 2003, Buechler et al. 2010). In addition, T-cadherin has been found to act as a receptor for hexameric and HMW forms of adiponectin (Hug et al. 2004, Hui et al. 2012). Specifically, AdipoR1 in pig tissues has been reported to be highly expressed (Kiezun et al. 2013), which is the reason why we focused on this subtype of AdipoRs. In addition, only Adipor1 knockdown has been found to be able to prevent the acute effects of the globular form of adiponectin on rat cardiac metabolism and oxidation (Palanivel et al. 2007). In the present study, the blockade of AdipoR1 through GTX89569-PEP reduced basal values of systo-diastolic function and cardiac perfusion in the absence of changes in the heart rate and aortic blood pressure. Hence, this is the first study showing those direct hemodynamic changes in response to an AdipoR1 blocker, which revealed an important role for AdipoR1 receptors in physiological control of cardiac function and perfusion in anesthetized pigs. In addition, further speculations could be raised if considering that WB analysis was able to detect a basal release of monomeric adiponectin in coronary blood flow of pigs; that is, basal monomeric adiponectin secretion could be involved in physiological modulation of cardiac function and perfusion through interaction with AdipoR1. Data obtained from experiments performed with GTX89569-PEP, that prevented all hemodynamic effects of adiponectin, would confirm that hypothesis. The role played by the AdipoR2, as well as the cell-surface glycoprotein T-cadherin should be examined in the future.

In conclusion, the results obtained in the present study highlight beneficial acute effects elicited by local human monomeric adiponectin administration on both heart function and perfusion. These findings are of particular relevance when considering that adiponectin is the most abundantly produced adipokine by adipose tissue, which surrounds the heart and blood vessels. Thus, adiponectin plays a protective role against cardiovascular disease not only by its action as insulin-sensitizing and anti-inflammatory agent, but also by direct positive effects on cardiac systo-diastolic function and myocardial perfusion, exerted via the modulation of the $\beta_{2}$-adrenoceptor-dependent NO release.

\section{Declaration of interest}

The authors declare that there is no conflict of interest that could be perceived as prejudicing the impartiality of the research reported.

\section{Funding}

This research has received generous sponsorship from Università del Piemonte Orientale 'A. Avogadro'.

Author contribution statement

The authors have participated actively in the study in terms of substantial contribution to design, analysis, and interpretation of data and manuscript drafting.

\section{Acknowledgements}

We thank the Azienda Ospedaliera Maggiore della Carità di Novara for its help.

\section{References}

Arita Y, Kihara S, Ouchi N, Takahashi M, Maeda K, Miyagawa J, Hotta K, Shimomura I, Nakamura T, Miyaoka K et al. 1999 Paradoxical decrease of an adipose-specific protein, adiponectin, in obesity. Biochemical and Biophysical Research Communications 257 79-83. (doi:10.1006/ bbrc.1999.0255)

Barseghian A, Gawande D \& Bajaj M 2011 Adiponectin and vulnerable atherosclerotic plaques. Journal of the American College of Cardiology $\mathbf{5 7}$ 761-770. (doi:10.1016/j.jacc.2010.11.011)

Bełtowski J, Jamroz-Wiśniewska A \& Widomska S 2008 Adiponectin and its role in cardiovascular diseases. Cardiovascular \& Hematological Disorders Drug Targets 8 7-46. (doi:10.2174/187152908783884920)

Bidulescu A, Liu J, Chen Z, Hickson DA, Musani SK, Samdarshi TE, Fox ER, Taylor HA \& Gibbons GH 2013 Associations of adiponectin and leptin with incident coronary heart disease and ischemic stroke in African Americans: the Jackson Heart Study. Frontiers in Public Health 24 1-16. (doi:10.3389/fpubh.2013.00016)

Buechler C, Wanninger J \& Neumeier M 2010 Adiponectin receptor binding proteins - recent advances in elucidating adiponectin signalling pathways. FEBS Letters $\mathbf{5 8 4} 4280-4286$. (doi:10.1016/ j.febslet.2010.09.035)

Bussey CT, Kolka CK, Rattigan S \& Richards SM 2011 Adiponectin opposes endothelin-1-mediated vasoconstriction in the perfused rat hindlimb. American Journal of Physiology. Heart and Circulatory Physiology $\mathbf{3 0 1}$ H79-H86. (doi:10.1152/ajpheart.00864.2010)

Chen H, Montagnani M, Funahashi T, Shimomura I \& Quon MJ 2003 Adiponectin stimulates production of nitric oxide in vascular endothelial cells. Journal of Biological Chemistry 278 45021-45026. (doi:10.1074/jbc.M307878200)

Cheng KK, Lam KS, Wang Y, Huang Y, Carling D, Wu D, Wong C \& Xu A 2007 Adiponectin-induced endothelial nitric oxide synthase activation and nitric oxide production are mediated by APPL1 in endothelial cells. Diabetes 56 1387-1394. (doi:10.2337/db06-1580)

Conti V, Russomanno G, Corbi G, Izzo V, Vecchione C \& Filippelli A 2013 Adrenoreceptors and nitric oxide in the cardiovascular system. Frontiers in Physiology 4 321. (doi:10.3389/fphys.2013.00321)

Eringa EC, Bakker W \& van Hinsbergh VW 2012 Paracrine regulation of vascular tone, inflammation and insulin sensitivity by perivascular adipose tissue. Vascular Pharmacology 56 204-209. (doi:10.1016/ j.vph.2012.02.003) 
Fang X, Palanivel R, Cresser J, Schram K, Ganguly R, Thong FS, Tuinei J, Xu A, Abel ED \& Sweeney G 2010 An APPL1-AMPK signaling axis mediates beneficial metabolic effects of adiponectin in the heart. American Journal of Physiology. Endocrinology and Metabolism 299 E721-E729. (doi:10.1152/ajpendo.00086.2010)

Fasshauer M, Klein J, Neumann S, Eszlinger M \& Paschke R 2001 Adiponectin gene expression is inhibited by $\beta$-adrenergic stimulation via protein kinase A in 3T3-L1 adipocytes. FEBS Letters 507 142-146. (doi:10.1016/S0014-5793(01)02960-X)

Fésüs G, Dubrovska G, Gorzelniak K, Kluge R, Huang Y, Luft FC \& Gollasch M 2007 Adiponectin is a novel humoral vasodilator. Cardiovascular Research 75 719-727. (doi:10.1016/j.cardiores.2007.05.025)

Frystyk J, Berne C, Berglund L, Jensevik K, Flyvbjerg A \& Zethelius B 2007 Serum adiponectin is a predictor of coronary heart disease: a population-based 10-year follow-up study in elderly men. Journal of Clinical Endocrinology and Metabolism 92 571-576. (doi:10.1210/jc. 2006-1067)

Grossini E, Molinari C, Mary DA, Uberti F, Caimmi PP \& Vacca G 2009 Intracoronary intermedin 1-47 augments cardiac perfusion and function in anesthetized pigs: role of calcitonin receptors and $\beta$-adrenoreceptor mediated nitric oxide release. Journal of Applied Physiology 107 1037-1050. (doi:10.1152/japplphysiol. 00569.2009)

Grossini E, Caimmi P, Molinari C, Uberti F, Mary D \& Vacca G 2011a Intracoronary gastrin 17 increases cardiac perfusion and function through autonomic nervous system, CCK receptors, and nitric oxide in anesthetized pigs. Journal of Applied Physiology 110 95-108. (doi:10.1152/japplphysiol.00625.2010)

Grossini E, Molinari C, Uberti F, Mary DA, Vacca G \& Caimmi PP 2011b Intracoronary melatonin increases coronary blood flow and cardiac function through $\beta$-adrenoreceptors, MT1/MT2 receptors, and nitric oxide in anesthetized pigs. Journal of Pineal Research 51 246-257. (doi:10.1111/j.1600-079X.2011.00886.x)

Grossini E, Molinari C, Morsanuto V, Mary D \& Vacca G $2013 a$ Intracoronary secretin increases cardiac perfusion and function in anaesthetised pigs through pathways involving $\beta$-adrenoceptors and nitric oxide. Experimental Physiology 98 973-987. (doi:10.1113/ expphysiol.2012.070607)

Grossini E, Surico D, Mary DA, Molinari C, Surico N \& Vacca G $2013 b$ In anesthetized pigs human chorionic gonadotropin increases myocardial perfusion and function through a $\beta$-adrenergic-related pathway and nitric oxide. Journal of Applied Physiology 115 422-435. (doi:10.1152/ japplphysiol.00425.2013)

Gu P \& Xu A 2013 Interplay between adipose tissue and blood vessels in obesity and vascular dysfunction. Reviews in Endocrine \& Metabolic Disorders 14 49-58. (doi:10.1007/s11154-012-9230-8)

Hara K, Yamauchi T, Imai Y, Manabe I, Nagai R \& Kadowaki T 2007 Reduced adiponectin level is associated with severity of coronary artery disease. International Heart Journal 48 149-153. (doi:10.1536/ihj.48.149)

Hug C, Wang J, Ahmad NS, Bogan JS, Tsao TS \& Lodish HF 2004 T-cadherin is a receptor for hexameric and high-molecular-weight forms of Acrp30/adiponectin. PNAS 101 10308-10313. (doi:10.1073/pnas. 0403382101)

Hui X, Lam KS, Vanhoutte PM \& Xu A 2012 Adiponectin and cardiovascular health: an update. British Journal of Pharmacology 165 574-590. (doi:10.1111/j.1476-5381.2011.01395.x)

Ignarro LJ 1989 Endothelium-derived nitric oxide: actions and properties. FASEB Journal 3 31-36.

Kiezun M, Maleszka A, Smolinska N, Nitkiewicz A \& Kaminski T 2013 Expression of adiponectin receptors 1 (AdipoR1) and 2 (AdipoR2) in the porcine pituitary during the oestrous cycle. Reproductive Biology and Endocrinology 11 18. (doi:10.1186/1477-7827-11-18)

Kojima S, Funahashi T, Otsuka F, Maruyoshi H, Yamashita T, Kajiwara I, Shimomura H, Miyao Y, Fujimoto K, Sugiyama S et al. 2006 Future adverse cardiac events can be predicted by persistently low plasma adiponectin concentrations in men and marked reductions of adiponectin in women after acute myocardial infarction. Atherosclerosis 194 204-213. (doi:10.1016/j.atherosclerosis.2006.07.028)

Kondo K, Shibata R, Unno K, Shimano M, Ishii M, Kito T, Shintani S, Walsh K, Ouchi N \& Murohara T 2010 Impact of a single intracoronary administration of adiponectin on myocardial ischemia/reperfusion injury in a pig model. Circulation. Cardiovascular Interventions 3 166-173. (doi:10.1161/CIRCINTERVENTIONS.109.872044)

Kumada M, Kihara S, Sumitsuji S, Kawamoto T, Matsumoto S, Ouchi N, Arita Y, Okamoto Y, Shimomura I, Hiraoka H et al. 2003 Association of hypoadiponectinemia with coronary artery disease in men. Arteriosclerosis, Thrombosis, and Vascular Biology 23 85-89. (doi:10.1161/ 01.ATV.0000048856.22331.50)

Lau WB, Tao L, Wang Y, Li R \& Ma XL 2011 Systemic adiponectin malfunction as a risk factor for cardiovascular disease. Antioxidants \& Redox Signaling 15 1863-1873. (doi:10.1089/ars.2010.3743)

Linden RJ \& Mary DA 1983 The preparation and maintenance of anaesthetized animals for the study of cardiovascular function. In Techniques in Cardiovascular Physiology, vol P3/1, pp 1-22. Ed RJ Linden. Shannon, UK: Elsevier Science.

Liu M \& Liu F 2012 Up- and down-regulation of adiponectin expression and multimerization: mechanisms and therapeutic implication. Biochimie 94 2126-2130. (doi:10.1016/j.biochi.2012.01.008)

Mao X, Kikani CK, Riojas RA, Langlais P, Wang L, Ramos FJ, Fang Q, ChristRoberts CY, Hong JY, Kim RY et al. 2006 APPL1 binds to adiponectin receptors and mediates adiponectin signalling and function. Nature Cell Biology 8 516-523. (doi:10.1038/ncb1404)

Mattu HS \& Randeva HS 2013 Role of adipokines in cardiovascular disease. Journal of Endocrinology 216 T17-T36. (doi:10.1530/JOE-12-0232)

Mazurek T, Zhang L, Zalewski A, Mannion JD, Diehl JT, Arafat H, Sarov-Blat L, O'Brien S, Keiper EA, Johnson AG et al. 2003 Human epicardial adipose tissue is a source of inflammatory mediators. Circulation $\mathbf{1 0 8}$ 2460-2466. (doi:10.1161/01.CIR.0000099542.57313.C5)

Negi SI, Jeong EM, Shukrullah I, Raicu M \& Dudley SC Jr 2012 Association of low plasma adiponectin with early diastolic dysfunction. Congestive Heart Failure 18 187-191. (doi:10.1111/j.1751-7133.2011.00276.x)

Ouchi N \& Walsh K 2007 Adiponectin as an anti-inflammatory factor. Clinica Chimica Acta 380 24-30. (doi:10.1016/j.cca.2007.01.026)

Ouwens DM, Sell H, Greulich S \& Eckel J 2010 The role of epicardial and perivascular adipose tissue in the pathophysiology of cardiovascular disease. Journal of Cellular and Molecular Medicine 14 2223-2234. (doi:10.1111/j.1582-4934.2010.01141.x)

Palanivel R, Fang X, Park M, Eguchi M, Pallan S, De Girolamo S, Liu Y, Wang Y, Xu A \& Sweeney G 2007 Globular and full-length forms of adiponectin mediate specific changes in glucose and fatty acid uptake and metabolism in cardiomyocytes. Cardiovascular Research $\mathbf{7 5}$ 148-157. (doi:10.1016/j.cardiores.2007.04.011)

Pischon T, Girman CJ, Hotamisligil GS, Rifai N, Hu FB \& Rimm EB 2004 Plasma adiponectin levels and risk of myocardial infarction in men. Journal of the American Medical Association 291 1730-1737. (doi:10.1001/jama.291.14.1730)

Shibata R, Sato K, Pimentel DR, Takemura Y, Kihara S, Ohashi K, Funahashi T, Ouchi N \& Walsh K 2005 Adiponectin protects against myocardial ischemia-reperfusion injury through AMPK- and COX-2-dependent mechanisms. Nature Medicine 11 1096-1103. (doi:10.1038/nm1295)

Shibata R, Numaguchi Y, Matsushita K, Sone T, Kubota R, Ohashi T, Ishii M, Kihara S, Walsh K, Ouchi N et al. 2008 Usefulness of adiponectin to predict myocardial salvage following successful reperfusion in patients with acute myocardial infarction. American Journal of Cardiology 101 1712-1715. (doi:10.1016/j.amjcard.2008.02.057)

Tan KC, Xu A, Chow WS, Lam MC, Ai VH, Tam SC \& Lam KS 2004 Hypoadiponectinemia is associated with impaired endotheliumdependent vasodilation. Journal of Clinical Endocrinology and Metabolism 89 765-769. (doi:10.1210/jc.2003-031012)

Tanida M, Shen J, Horii Y, Matsuda M, Kihara S, Funahashi T, Shimomura I, Sawai H, Fukuda Y, Matsuzawa Y et al. 2007 Effects of adiponectin on http://joe.endocrinology-journals.org DOI: 10.1530/JOE-14-0170
() 2014 Society for Endocrinology Printed in Great Britain 
the renal sympathetic nerve activity and blood pressure in rats. Experimental Biology and Medicine 232 390-397.

Tao L, Gao E, Jiao X, Yuan Y, Li S, Christopher TA, Lopez BL, Koch W, Chan L, Goldstein BJ et al. 2007 Adiponectin cardioprotection after myocardial ischemia/reperfusion involves the reduction of oxidative/ nitrative stress. Circulation 115 1408-1416. (doi:10.1161/CIRCULATIONAHA.106.666941)

Tune JD, Gorman MW \& Feigl EO 2004 Matching coronary blood flow to myocardial oxygen consumption. Journal of Applied Physiology $\mathbf{9 7}$ 404-415. (doi:10.1152/japplphysiol.01345.2003)
Xu A, Wang Y, Lam KS \& Vanhoutte PM 2010 Vascular actions of adipokines molecular mechanisms and therapeutic implications. Advances in Pharmacology 60 229-255. (doi:10.1016/B978-0-12-385061-4.00008-8)

Yamauchi T, Kamon J, Ito Y, Tsuchida A, Yokomizo T, Kita S, Sugiyama T, Miyagishi M, Hara K, Tsunoda M et al. 2003 Cloning of adiponectin receptors that mediate antidiabetic metabolic effects. Nature $\mathbf{4 2 3}$ 762-769. (doi:10.1038/nature01705)

Zhu W, Cheng KK, Vanhoutte PM, Lam KS \& Xu A 2008 Vascular effects of adiponectin: molecular mechanisms and potential therapeutic intervention. Clinical Science 114 361-374. (doi:10.1042/CS20070347)

Received in final form 7 May 2014

Accepted 16 May 2014

Accepted Preprint published online 23 May 2014
Published by Bioscientifica Ltd. 